\title{
Experimental Investigation of the Effect of Vibrator Machine for Desilting Sediment in the Pressure Flushing
}

\author{
A. A. Dodaran ${ }^{1}$, S. K. Park ${ }^{2 *}$, and A. Mardashti ${ }^{3}$ \\ ${ }^{1,2}$ Department of Civil Engineering, Pusan National University, Busan, South Korea \\ ${ }^{3}$ Department of Water Engineering, Shiraz University, Shiraz, Iran
}

Received 31 December 2013, accepted in revised form 24 August 2014

\begin{abstract}
As natural streams enter reservoirs, the stream's flow depth increases and the flow velocity decreases. Itdecreases the sediment transport capacity of the stream and causes settling. Numerous methods have been planned to control the sedimentation process. These may include catchment's management, flushing, sluicing etc. Flushing is used to erode previously deposited sediments. When outlet is opened the sediment in the vicinity of the outlet openings is scoured and a funnel shaped crater is created.In this research experimental studywas performed to investigatethe effect of localized vibrations in the sediment layers on the dimensions of the flushing cone. For this purpose laboratory test was carried out under different hydraulic conditions such as five discharges of $0.23,0.53,1.21$, 1.53 and $2.1 \mathrm{lit} / \mathrm{s}$ with bottom outlets with diameters of 1 and 2 inch. Using the vibrator machine mounted in the reservoir and close to the bottom outlet, different frequencies(e.g. 20,35 and $50 \mathrm{~Hz}$ ) have been applied for the deposited sediment in the vicinity of the outlet. The results showthat, the dimension offlushing cone significantly increaseddue tovibrations.
\end{abstract}

Keywords: Flushing; Localized Vibration; Frequency; Sedimentation.

C 2014 JSR Publications. ISSN: 2070-0237 (Print); 2070-0245 (Online). All rights reserved.

doi: http://dx.doi.org/10.3329/jsr.v6i3.17236 J. Sci. Res. 6 (3), 475-485 (2014)

\section{Introduction}

Almost $1 \%$ of the storage volume of the world's reservoirs is lost yearly due to sediment deposition. In Iran and some developing countries, where watershed organization measures are not accomplished effectively, basin storage is being lost at much larger rates. Though the decrease of sediment yield via a watershed management program is the greatest option for reducing the rate of reservoir sedimentation, flushing may be one of the most economic methods, offering recovery of lost storage without incurring the

*Corresponding author: sakpark@pusan.ac.kr 
expenditure of dredging or additional mechanical means of removing sediment. Pressure flushing is the scouring out of dropped sediments from dams through the use of low level outlets in a dam by lowering water levels, and thus increasing the flow velocities in the reservoir. Sustaining the storage capacity of existing reservoirs has become a more important issue than building new reservoirs, which is difficult due to strict environmental regulations, high costs of construction, and lack of suitable dam sites [9]. Numeroustechniques have been planned to managementthe sedimentation process. These include catchment's management, flushing, sluicing, density current venting and dredging. Flushing is used to erode previously deposited sediments Brandt [1].

One of the most effective techniques is flushing through which the deposited sediment is hydraulically removed by the flow. The oldest known method of flushing, practiced in Spain in the 16th century, was referred to Brown [2]. The increase of shear force of accelerated flows created by sudden opening of the bottom outlets of dams loosens and resuspends the sediment. The flow will then wash them up from the system. If flushing takes place under a pressurized this flushing is called pressure flushing and has only local effects around the outlet. Duringpressure flushing of deposited sediments over large dam intakes, a funnel shaped crater is created due to considerable shear flow around opening [5]. Fig. 1, illustrates the longitudinal view of a flushing cone in the vicinity of the bottom outlet.Pressurized flushing has been studied extensively in the literature White [10], Shen and Lai [7], Fang and Cao [6], Scheuerlein [8], Fathi-Moghadam [5], and Emamgholizadeh $[3,4]$. In spite of advances in the investigation of pressure flushing technique, studies about the effect of bottom outlet diameter on flushing cone dimensionsare limited about this phenomenon is needed.

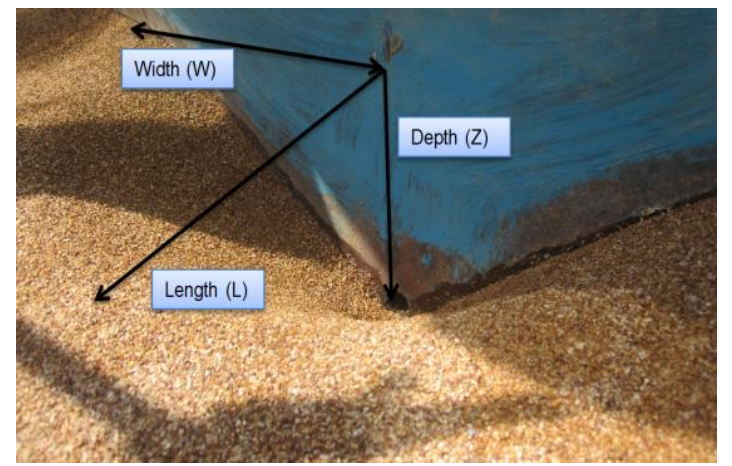

Fig. 1. illustrates the longitudinal view of flushing cone in the vicinity of the bottom outlet.

Estimation of flushed sediment (or dimension of flushing cone) is important for designing of bottom outlet gates, so that the optimum bottom outlet can be designed. Research evaluating the geometric characteristics of scouring cones against various cross sections of the bottom outlet is necessary for the proper design of the bottom 
outlet.Moreover, dimensions of the flushing cone are also important for the rescue of power plant intakes. This paper deals experimentally with pressure flushing phenomena and investigates the effect of bottom outlet on volume and dimensions of the flushing cone. The results are tabulated in terms of statistical measures and also illustrated in the scatter plots.This paper also experimentally focuses on temporal evolution of scouring cone dimensions during the pressure flushing process according to with vibration position and different frequency. The objective of this study is to present procedures for computing the temporal variation of flushing cone geometry (i.e., depth, width and length, frequency) in the vicinity of the bottom outlet during pressure flushing.

\section{Materials and Method}

\subsection{Test procedure and set-up}

The tests were conducted at the hydraulic laboratory of Shiraz University in Iran. The test apparatus involves four parts: water supply system, bottom outlet, settling basin reservoir, and V-notch weir.Experimental tests were carried out in a hexahedral shallow basin whose overall dimensions were $7 \mathrm{mlong}, 1 \mathrm{~m}$ wide and $1 \mathrm{~m}$ high. Using two reticulate sheets at the reservoir's entrance, a smooth flow is created. The front wall of the model will be easy to modify for different cross sections of reservoir bottom outlets. The outlets of the main reservoir include two different gate valves with diameters of 1 inch and 2 inch $\mathrm{cm}$. The sediment deposits at the main reservoir consisted of silica particles with uniform size distribution, with a median diameter of $d_{50}=1 \mathrm{~mm}$ and geometric standard deviation of $\sigma=1.25$.Adjacent to the reservoir, an underground tank as well as a pump was used to prepare and recirculate the desired inflow water discharge, which is called the water supply system. The water supply system of the model was also supported by an adjusting valve, a digital flow-meter, and an $11 \mathrm{~m}$ flume upstream of the model. Along the basin side walls, a movable frame was mounted to carry the measuring instruments. The scour cone configuration was measured by a digital point gage device.
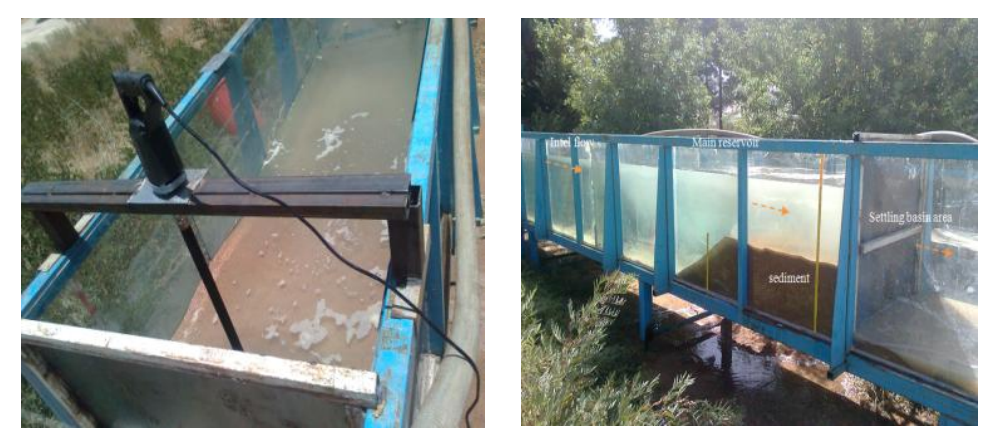

Fig. 2. The experimental setup and the hydraulic circuits. 
For the downstream section, another stilling basin was used in which the mixing flow of water and sediment was collected and through a plastic pipe in a closed circuit with the underground tank. The settling basin was a rectangular flume $4 \mathrm{~m}$ long, $1 \mathrm{~m}$ wide, and $1 \mathrm{~m}$ high. At the end of the settling reservoir there was a V-notch weir (with an angle of $90^{\circ}$ ) to measure outflow discharge. In Figs. 2 and 3 a schematic plan view of the experimental setup and the hydraulic circuits is given. The notation of flushing half- cone under a discharge of $2 \mathrm{lit} / \mathrm{s}$, water depth of $80 \mathrm{~cm}$ and $5.08 \mathrm{~cm}$ diameter of the outlet are illustrated (see Fig. 4).

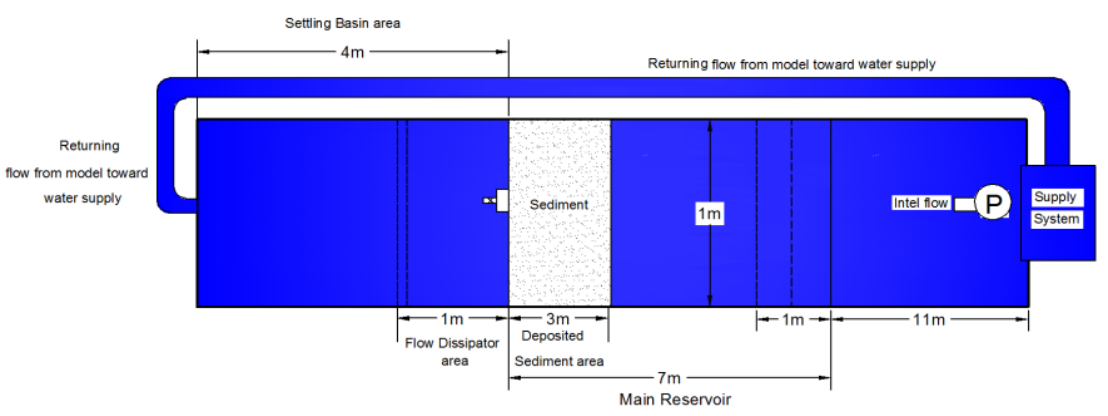

Fig. 3. A schematic plan view of the experimental setup and the hydraulic circuits.

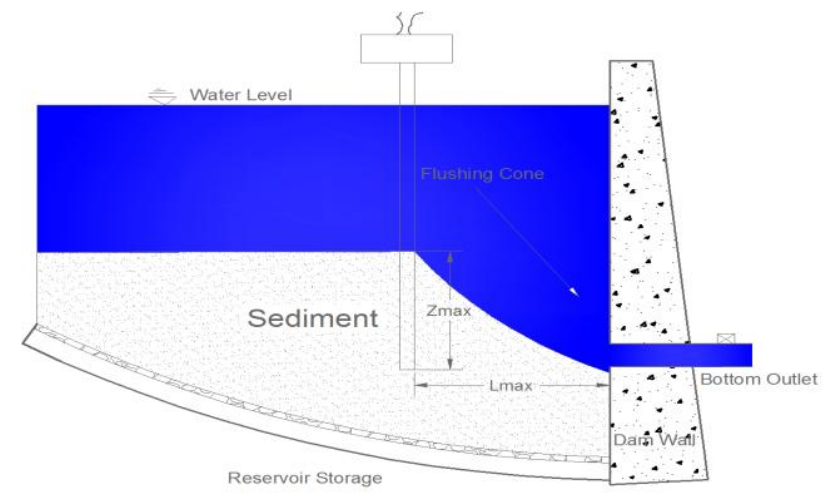

Fig. 4. Longitudinal of experimental setup and illustrated diameter of the outlet.

Research was continued until the flushing cone reached an equilibrium (at which point no further particle motion was observed) condition in which the sediment concentration was negligible at the end of the experiment. The time required for the formation of the flushing cone depends on hydraulic conditions. For this purpose, the objectives of present study were to conducta laboratory test under different hydraulic conditions, such as two bottom outlets with diameter equal to $2.54 \mathrm{~cm}(1$ inch) and $5.08 \mathrm{~cm}(2$ inch), five 
discharges of $0.23,0.53,1.21$ and $2.1 \mathrm{lit} / \mathrm{s}$. Using the vibrator machine mounted in the reservoir and close to the bottom outlet, different frequencies (e.g. 20, 35, $50 \mathrm{~Hz}$ ) have been applied to the deposited sediment in the vicinity of the outlet. Firstly, deposited sediments were until they reached a specific level above the bottom outlet $(35 \mathrm{~cm})$, and then the model was gradually filled with water until the water surface elevation reached the desired level. Then, the bottom outlet was physically opened so that the outflow discharge being equal to the inflow discharges. As a result, sediments were released from main reservoir. Experiments were stopped at the end of different test durations (e.g., 5, 10, 20, 30, 50, 80 and 200 seconds) to determine the contours and dimensions of the scour cone. The development of a flushing cone was very fast, and the process finished between one minute and ten minutes in the experimental model. In this study, the time for running the experiment was set to 45 minute. At the end of each experiment, the flushing outlet was closed and the incoming discharge was set to zero, then water was carefully and slowly drained from the main reservoir. After the end of each experiment, the bed level of scouring was measured using digital point gages, and the volume of flushing cone was calculated by Surfer 9.0 software.

\subsection{Vibration position}

Position of a vibration machine and a plan longitudinal profile are illustrated (Freq $=20$, 35 and $50 \mathrm{HZ}$ ) in Fig. 3. The vibrator is provided with a built-in converter in the switch box that converts the frequency from $10 \mathrm{~Hz}$ to $50 \mathrm{~Hz}$, and 1-phase $220 \mathrm{~V}$ to 3-phase 210 $\mathrm{V}$ shown in Table 1, which runs the 3-phase motor in the poker. As the poker vibrator is connected to a 1-phase wall socket-outlet, it can be used everywhere. The comfortable start/stop knobs on the front side of the switch box are easily reached. The converter in the switch box has built-in functions that protect the equipment and the user against operational hazards. The strong, user-friendly switch box of impact resistant aluminum is designed to withstand the tough construction environment.

Table 1. Poker vibrator details.

\begin{tabular}{|llll|}
\hline \multicolumn{4}{|c|}{ Main Technical Parameter } \\
\hline Model & ZN25 & ZN35 & ZN50 \\
\hline Input Power & $550 \mathrm{~W}$ & $750 \mathrm{~W}$ & $1300 \mathrm{~W}$ \\
\hline Rated Current & $2.2 \mathrm{~A}$ & $2.8 \mathrm{~A}$ & $3.5 \mathrm{~A}$ \\
\hline Power Supply & $220 \mathrm{~V}, 50 \mathrm{~Hz}$, & $220 \mathrm{~V}, 50 \mathrm{~Hz}$, & $220 \mathrm{~V}, 50 \mathrm{~Hz}$, \\
& Single-phase & Single-phase & Single-phase \\
\hline Matched & $25 \times 1 \mathrm{~mm}$ & $35 \times 1 \mathrm{~mm}$ & $50 \times 1 \mathrm{~mm}$ \\
Vibrator Poker & & & \\
\hline
\end{tabular}




\section{Dimensional Analysis}

The funnel-shaped crater in pressurized flushing is characterised by many parameters. During the experiment, in a given time, the length of scour at time $\left(L_{t}\right)$ shown in Eq. 1 is a function of the following variables:

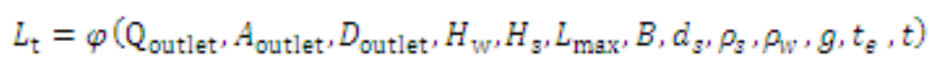

Fig. 3 demonstrates the notation of flushing cone dimensions at the vicinity of bottom outlet. Through a dimensional analysis, the ratio of scouring length to its maximum value $\left(L_{\mathrm{t}} / L_{\max }\right)$, as shown in Eq. 2, can be mathematically expressed as:

$$
\frac{L_{\mathrm{t}}}{L_{\mathrm{max}}}=\varphi\left(\frac{\frac{Q_{\text {gutlat }}}{A_{\text {gutlat }}}}{\sqrt{g H_{\mathrm{WV}}}} \frac{H_{g}}{d_{g}}, \frac{D_{\text {outlet }}}{B}, \frac{\rho_{\mathrm{w}}}{\rho_{s}}, \frac{t}{t_{\mathrm{e}}}\right)
$$

In this studythe parameters $H_{\mathrm{s}}, D_{\text {outlet }}, B, d s, \rho_{s}, \rho_{w}$ and $\mathrm{g}$ are constant. Hence, Eq. 2 can be shortened as (Eq. 3):

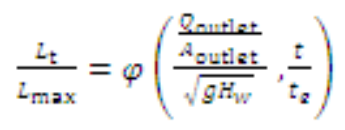

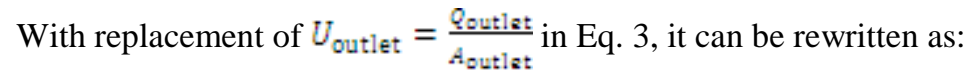

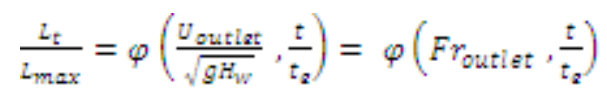

Using the same process, the depth and width of flushing cone can be expressed as Eqs. 5 and 6:

$$
\begin{aligned}
& \frac{z_{\mathrm{t}}}{z_{\max }}=\varphi\left(F x_{\text {outlet }} \frac{\mathrm{t}}{t_{\mathrm{z}}}\right) \\
& \frac{W_{E}}{W_{\max }}=\varphi\left(F x_{\text {outlet }} \cdot \frac{t}{t_{z}}\right)
\end{aligned}
$$

\section{Results and Discussion}

Fig. 5 displays the variation of $L / L_{\max }$ against $t / t_{\mathrm{e}}$ with different frequencies of vibration (e.g. 0, 20, 35 and $50 \mathrm{~Hz}$ ) for all groups of experiments. It is clear that by increasing t/te and frequency the scour length increases. The scattering of data also shows that the data can be classified in two groups according to Froude number. The limit value for 
classification is 0.7. By a regression analysis, shown in Eqs. 5 and 6 were obtained for assessing the scour length. The results show that frequency of vibration is the main parameters affecting the flushing cone dimensions and with increase of vibration frequency, the dimensions of flushing cone (volume, length and width) are increased. Based upon experimental data, dimensionless equations for prediction of flushing cone parameters are presented. These equations have high correlation coefficients and a good estimate. The initial research showed that selecting the appropriate frequency and appropriate position vibrator will be the best option to rescue the power plant intakes. The variations of calculated and measured scour length using proposed equations are presented in Fig. 5. Figs. 6 and 7 display the variations of $W / W_{\max }$ and $Z / Z_{\max }$ with $t / t_{\mathrm{e}}$, respectively, and dimensions of the flushing cone at the vicinity of bottom outlet are illustrated in Fig. 7. It is clear that an increasing $t / t_{\mathrm{e}}$ and frequency will also increase the depth and width of flushing cone. Fig. 8 displays the numerical and experiment al variations of the flushing cone at the vicinity of bottom with vibration frequency 0 and $50 \mathrm{~Hz}$, respectively.

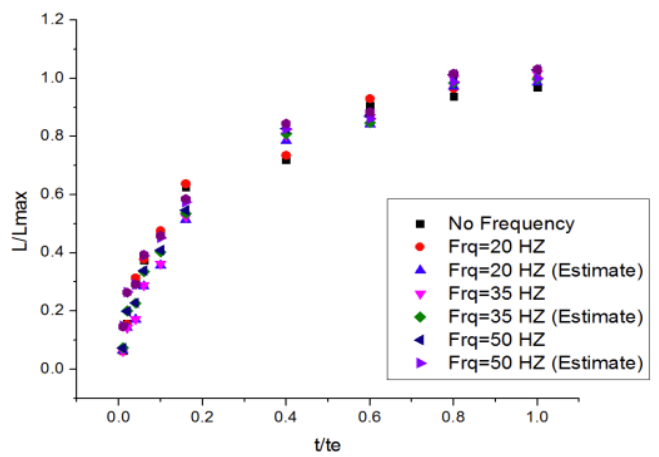

Fig. 5. The time variations of calculated and measured scour length.

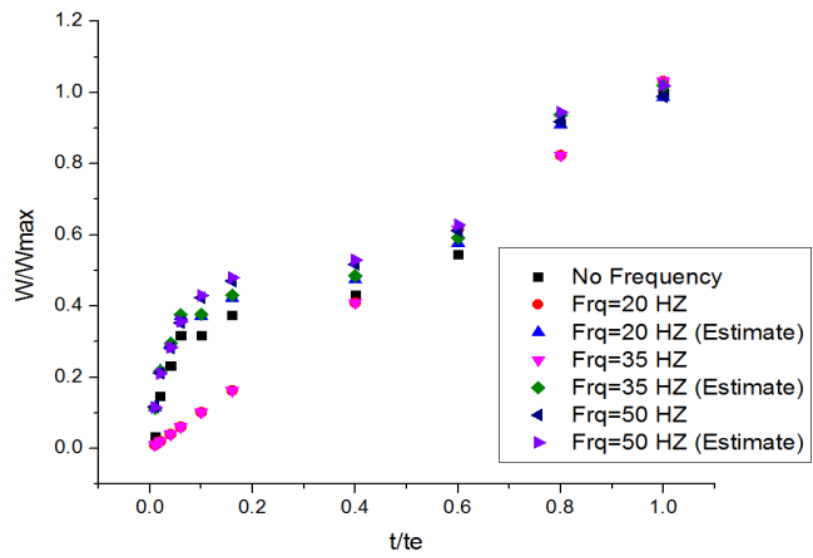

Fig. 6. Demonstrationthe variations of $W / W_{\max }$ with $t / t_{\mathrm{e}}$. 


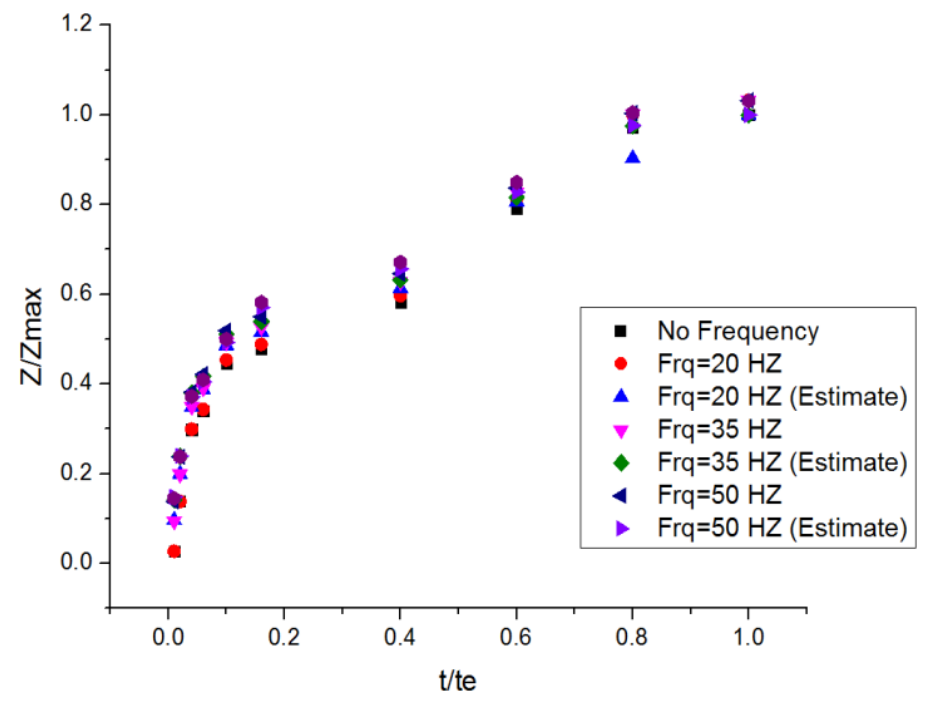

Fig. 7. Demonstrationthe variations of $Z / Z_{\max }$ with $t / t_{\mathrm{e}}$.

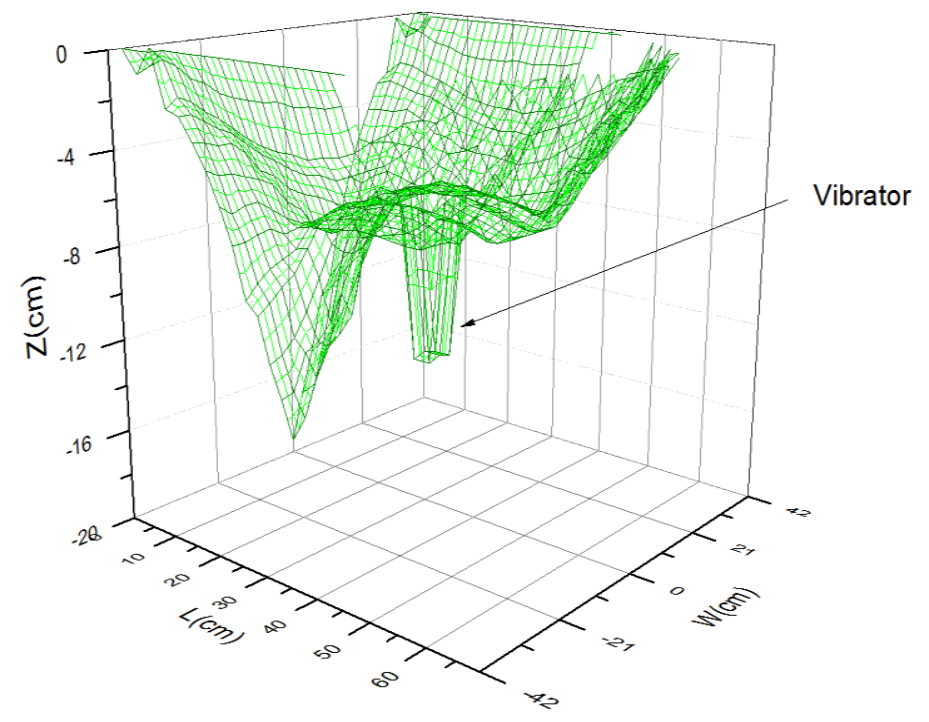

Fig. 8. Dimensions of the flushing cone at the vicinity of bottom outlet. 

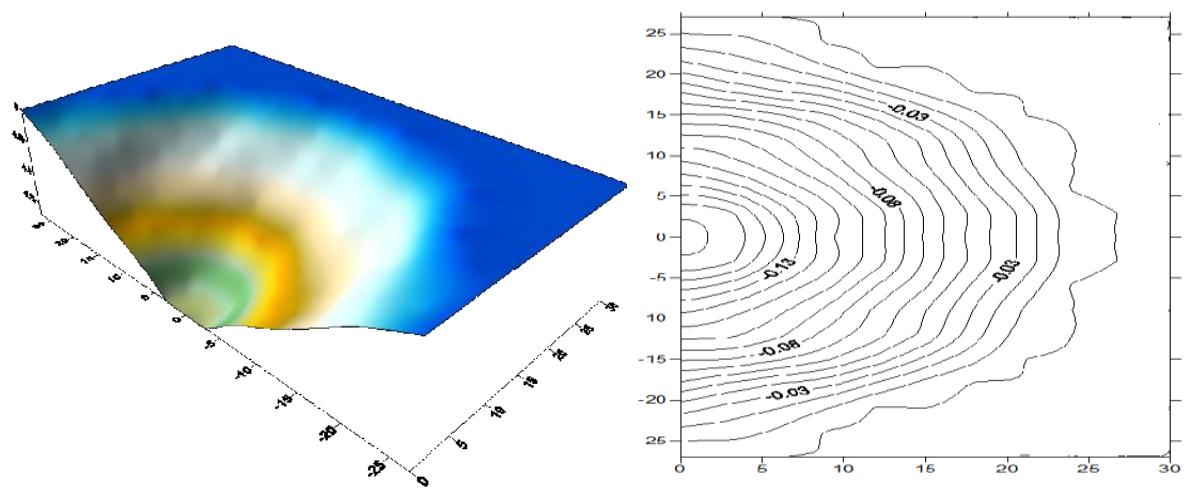

(a)
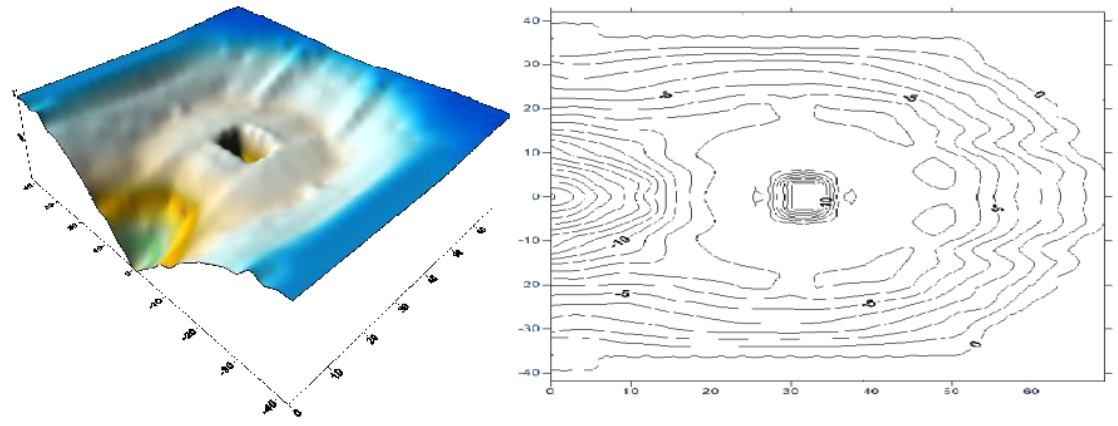

(b)

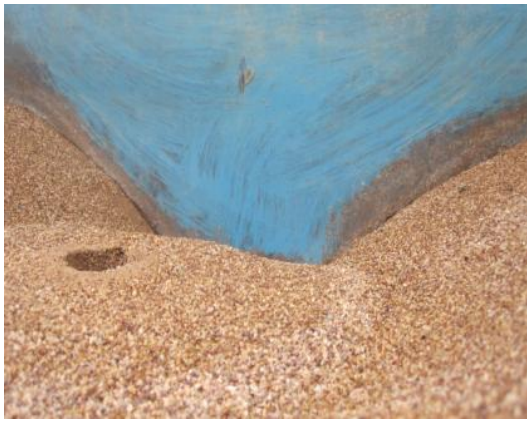

(c)

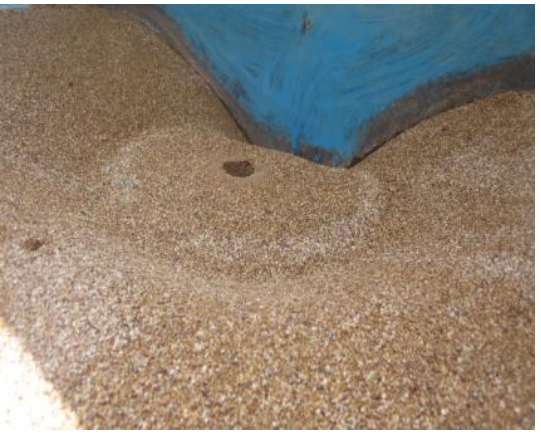

(d)

Fig. 8. Experimental of the flushing cone at the vicinity of bottom with vibration frequency 0 and $50 \mathrm{~Hz}$, respectively (a and b, c and d).

Fig. 9 shows the ratio of the length versusdischarge of the cavity flushing for the position of without vibration and vibration (freq $=0,20,35$ and $50 \mathrm{~Hz}$ ) and the fixed hydraulic parameters which were in this experiment, a constant water height $80 \mathrm{~cm}$, height of sediment $40 \mathrm{~cm}$, and valves 
gate diameter 1 and 2 inch. As was clear from Fig. 9, by increasing the length of cone in a fix valve gate, the discharge of the cone flushing went up, also by increasing the diameter of valves gate from 1 to 2 inch, length of the cone flushing increased significantly.
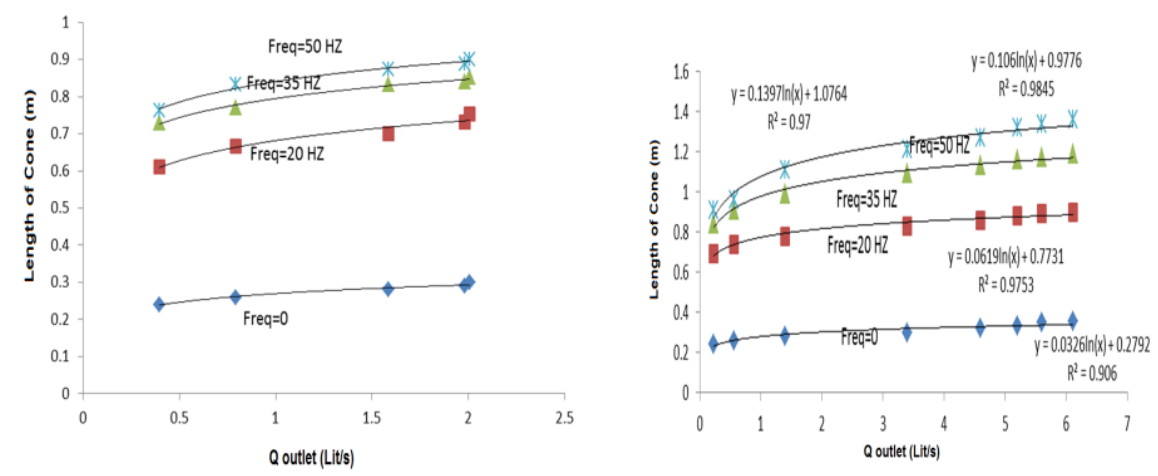

Fig. 9. Illustration of length core versus discharge 1, 2 inch.

\section{Conclusions}

$A_{\text {Outlet }}$ and freq are the key factors in correlating the flushing cone dimensions in this study. With increase of diameter of bottom outlet and frequency, the results indicate that the length and width and depth of flushing cone are strongly affected by vibrations and the time dependent geometric features of flushing cone. The present equations have high correlation coefficient and in spite of their correlation their applicability should be tested using other experimental and field data. Further experiments are necessary using different size, shape and graduation of bed material, and under different hydraulic conditions to confirm the results obtained from this study.

\section{Acknowledgements}

This work was supported by Brian Korean 21 Grant of Pusan National University.

\section{References}

1. S. A. Brandt, Intern. J. Sediment Res. 15 (2), 321 (2000).

2. C. B. Brown, The Control of Reservoir Silting, United States Department of Agriculture, Miscellaneous Publication No. 521, Washington, D.C. 1943, p. 166.

3. S. Emamgholizadeh,, M. Bina, M. Fathimoghadam, and M. GHomeyshi, ARPN J. Eng. Appl. Sci. 1 (4) (2006). http://www.hach.ulg.ac.be/cms/en/system/files/Emamgholizadeh 2006.pdf

4. S. Emamgholizadeh, H. Samadi, and M. Bina The flushing of the sediment near the powerintakes in the Dez Reservoir,River Basin Management, Italy (2005).

5. M. Fathi-Moghadam, S. Emamgholizadeh, M. Bina, M. Ghomeshi, J. Hydrau. Res. 48 (4), 509 (2010). DOI:10.1080/00221686.2010.491691 
6. D. Fang and S. Cao, An experimental study on scour funnel in front of a sediment flushing outlet of a reservoir, Proc. of the 6th Federal Interagency Sedimentation Conference. (1996)

7. H. W. Shen, J. S. Lai, and D. Zhao, Hydraulic desiltation for non-cohesive sediment, Proc. of the 1993 Annual ASCE Hydraulic Engineering Conference, San Francisco, H.W Shen, S.T. Su, and F. Wen (Eds.) (1993) pp. 119-124.

8. H. Scheuerlein, M. Tritthart, and F. N. Gonzalez, Numerical and physical modeling concerning the removal of sediment deposits from reservoirs, Conf. proceeding of Hydraulic of Dams and River Structures, Tehran, Iran (2004).

9. H. W. Shen, and J. S. Lai, Intern. J. Sediment Res. 11 (3), 10 (1996).

10. W. R. White and R. Bettess, The feasibility of flushing sediments through reservoirs, Challenges in African Hydrology and Water Resources, Proceeding of Harare Symposium, July, D. E. Walling, S. S. D. Foster, P. Wurzel (Eds.) (1984). 